\title{
Estimating the Absorbed Dose in Spinal Cord After Radiotherapy of Cervical Esophageal Tumors (Dose measurement at 3D Plexiglas phantom)
}

ISSN: 2637-773X

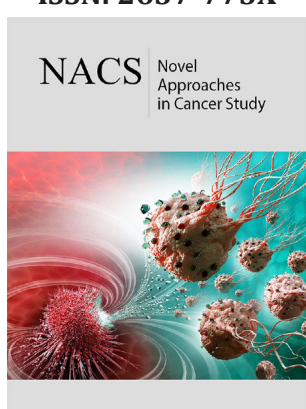

*Corresponding author: Mahdi Heravian Shandiz, Department of Biomedical Engineering, Mashhad University of Medical Sciences, Iran

Submission: 些 August 05, 2019

Published: 漹October 30, 2019

Volume 3 - Issue 4

How to cite this article: Safaeian $\mathrm{GH}$ BahreyniToossi MT, Feyzi A, Asadinezhad M, Heravian Shandiz M* $^{*}$ et al. Estimating the Absorbed Dose in Spinal Cord After Radiotherapy of Cervical Esophageal Tumors (Dose measurement at 3D Plexiglas phantom). Nov Appro in Can Study. 3(4). NACS.000568.2019. DOI: $10.31031 /$ NACS.2019.03.000569

Copyright@ Mahdi Heravian Shandiz, This article is distributed under the terms of the Creative Commons Attribution 4.0 International License, which permits unrestricted use and redistribution provided that the original author and source are credited.

\section{Safaeian $\mathrm{GH}^{1}$, BahreyniToossi $\mathrm{MT}^{2}$, Feyzi $\mathrm{A}^{3}$, Asadinezhad $\mathrm{M}^{4}$, Heravian Shandiz $\mathbf{M}^{5 *}$ and Alireza $\mathbf{R K}^{6}$}

${ }^{1}$ Department of Radiation Technology, School of Paramedical Sciences, Mashhad University of Medical Sciences, Mashhad, Iran

${ }^{2}$ Medical Physics Research Center, Faculty of Medicine, Mashhad University of Medical Sciences, Mashhad, Iran

${ }^{3}$ Department of radiology, School of Medicine, Mashhad University of Medical Sciences, Mashhad, Iran

${ }^{4}$ Department of Radiation Technology, School of Paramedical Sciences, Mashhad University of Medical Sciences, Mashhad, Iran

${ }^{5}$ Department of Radiation Technology, School of Paramedical Sciences, Mashhad University of Medical Sciences, Mashhad, Iran

${ }^{6}$ Department of Pharmacodynamics and Toxicology, Mashhad University of Medical Sciences, Mashhad, Iran

\section{Abstract}

Background: The objective of this study was to estimate the dose received by the spinal cord and the esophagus by the use of TLD in a Plexiglas phantom.

Methods: The study was carried out with a Plexiglas phantom that was specifically designed for this purpose. Three Plexiglas phantoms of the neck and upper mid thoracic area were built based on the specifications of "reference man" and Body Mass Index (B.M.I) by the use of Corel Draw 8 software. The phantoms were heavy, medium and light built in size. The dose was determined by placing TLD cheaps at each marked location inside each phantom and exposing them to radiation for ten different set-ups.

Results: Based on different measurements it was concluded that using a gantry angle of 57o, a 30o wedge and a 15 o rotation of the head of the table toward the gantry head will result in esophagus and spinal cord receiving the maximum and minimum dose respectively.

Conclusion: Based on our results a better dose homogeneity is achieved for dose delivered to esophagus than corresponding values for spinal cord.

Keywords: Radiotherapy; Phantom; Plexiglas; Absorbed dose; TLD

Introduction

In radiotherapy there is a great need for accurate determination of the adsorbed dose of tumor tissue as well as to healthy organs at risk. The absorbed dose delivered to the planning target volume (PTV) should be $\pm \% 5$ of the stated dose (Other authors suggest $\pm \% 3$ ) $[1,2]$. To accomplish this goal, most treatments are executed according to a calculated plan. In clinical cases verification of the calculated dose plan by measurements is often complicated. This is especially true if the treatment comprises several beams of different fields and radiation qualities and if the beams impinge on an irregularly shaped body section containing various kinds of tissues or cavities. One method to verification treatments is to carry out measurements using thermo luminescence (TL) dosimeters in patient-like (soft tissue equivalent) phantoms $[2,3]$. The purpose of this study was to estimate the absorbed dose in the spinal cord and the esophagus by the TLD measurements in Plexiglas phantom.

\section{Materials and Method}

\section{Design of phantoms}

Radiation therapy of lesions in the upper third of the esophagus, involves serious technical problems, this is due to the changing contour from neck to the thoracic inlet and the proximity 
of esophagus to spinal cord [3].Usually, these lesions are treated from the laryngo pharyngeal to the carina with anterior wedged oblique fields. The radiotherapy technique applied to this region must take into account the tolerance level of spinal cord $[3,4]$. This study was carried out with three Perspex (Plexiglas) phantoms that were specifically designed for this purpose. Plexiglas was chosen because it is relatively soft tissue equivalent and cheap, easily machined and useful for constructing phantoms of varying shapes [1]. PMMA (Poly Methyl Metha Acrylic,) is a material that has the same radiation attenuation property as soft tissue [1,2]. Three Plexiglas phantoms of the neck and upper mid thoracic area were built based on the specifications of "reference man" and body mass index (B.M.I) by the use of Corel Draw 8 software. The phantoms were heavy, medium and light built in size (Figure 1).

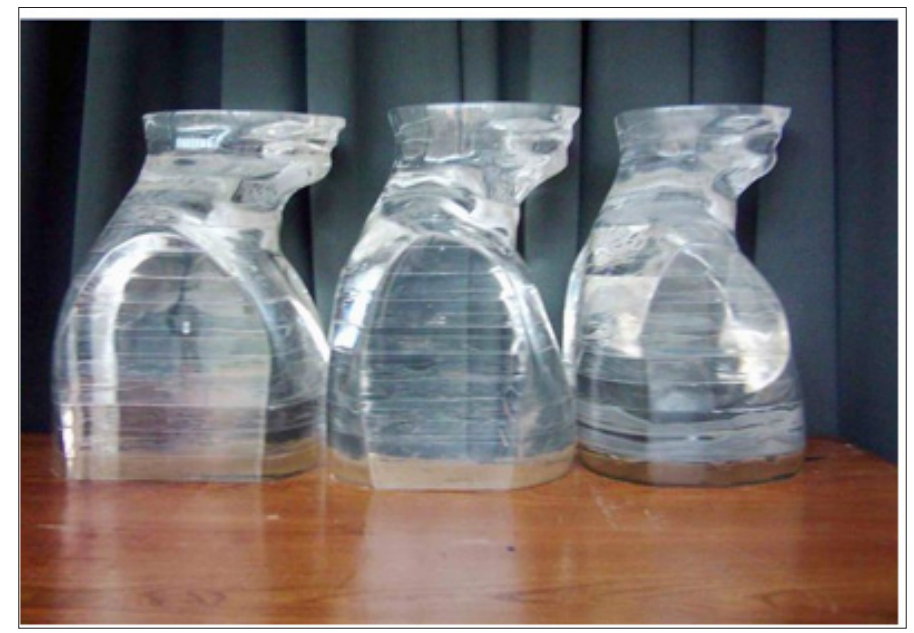

Figure 1: Plexiglas phantoms of the neck and upper mid thoracic area.

\section{Dose measurement}

Dose measurements were carried out by the applications of the following Equipment's [5,6]:

a. TLD-100 cheaps (LiF: Mg,Ti )made by Harshaw [5].

b. TLD Reader (Harshaw -Model 3500) [6].

c. Co-60 Unit (Model Theratron 780 -AECL -Canada), linear accelerator (6Mev- varian).

d. A set of three Plexiglas Phantoms (Figure 1).
CT scanning of the phantoms were performed by a Siemens Somatom Plus-s, 64 slice, rotate-rotate machine of the third generation(Figure 2).Locations of esophagus and spinal cord in the upper, middle and lower parts of radiation fields were determined by the CT scan radiographs of an Rondo Alderson phantom (reference man). Ten different set-ups were planned. TLD cheaps were inserted in preselected holes inside the specified region of the phantoms. At this stage phantoms were irradiated by application of two right and left anterior oblique wedged fields (Table 1). The phantom was then CT scanned, and a dose plan was generated using the obtained CT data (Figure 2).

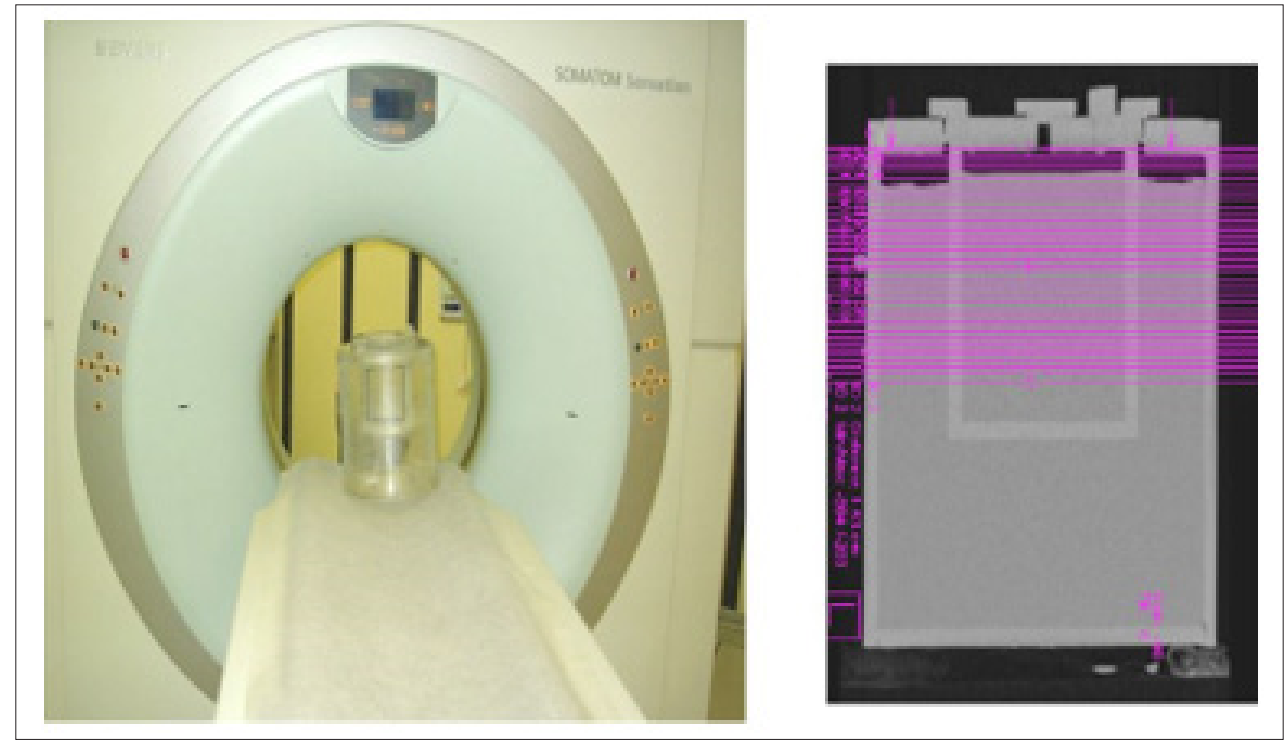

Figure 2: CT and dose plan of the phantom. 
Table 1: Irradiation parameters forupper third of theesophagus cancer treatment (Two fields).

\begin{tabular}{|c|c|c|c|c|}
\hline Treatment Time (Min) & (SSD) (cm) & Field Size (cm) & Prescribed Dose from One Field (cGy) & Technique \\
\hline 1.8 & 80 & $6 \mathrm{~W} \times 18$ & 100 & R\&L anterior oblique wedge \\
\hline
\end{tabular}

\section{Result}

In this study dose distribution of a clinical treatment procedure produced by ten different set-ups and two techniques (right and left anterior oblique wedged and AP-PA fields).The dose was determined by placing TLD cheaps (TLD-100) at each marked location inside each phantom and exposing them to radiation for any set-up. With the anterior oblique wedged fields technique, the mean spinal cord dose was significantly lower compared to esophageal dose (P-value<0.001). While for AP-PA techniques, as was illustrated in figure 3 , the mean spinal cord dose is more than esophageal dose. Therefore, this technique (anterior oblique wedge fields) is preferred to AP-PA technique. For all three phantoms, a gantry angle of $57^{\circ}$, a $30^{\circ}$ wedge and a $15^{\circ}$ rotation of the table toward the gantry head, resulted in the esophagus and the spinal cord receiving maximum and minimum dose respectively (Figure 3,4,) (Table 2).

Table 2: Comparison of mean absorbed dose of Spinal cord and esophagus in different set-ups for all three Phantoms with t-test.

\begin{tabular}{|c|c|c|c|c|c|}
\hline \multirow{3}{*}{ t-Test Result } & \multicolumn{4}{|c|}{ Dose (rad) } & \multirow{3}{*}{$\begin{array}{c}\text { Organ } \\
\text { Index Situation }\end{array}$} \\
\hline & \multicolumn{2}{|c|}{ Esophagus } & \multicolumn{2}{|c|}{ Spinal Cord } & \\
\hline & SD & Mean & SD & Mean & \\
\hline $\mathrm{t}=-0.932 \mathrm{P}-$ Value $=0.355$ & 25.41 & 229.76 & 44.27 & 221.08 & Upper \\
\hline $\mathrm{t}=-12.875 \mathrm{P}-$ Value $=0.000$ & 14.13 & 204.16 & 43.79 & 96.01 & Middle \\
\hline \multirow[t]{2}{*}{$\mathrm{t}=-11.204 \mathrm{P}-$ Value $=0.000$} & 11.42 & 156.98 & 39.01 & 73.83 & Lower \\
\hline & \multicolumn{2}{|c|}{$\mathrm{F}=125.732$ P-Value $<0.001$} & \multicolumn{2}{|c|}{$\begin{array}{c}\mathrm{F}=105.082 \mathrm{P}-\text { Value }< \\
0.001\end{array}$} & $\begin{array}{c}\text { Analysis of variance } \\
\text { result }\end{array}$ \\
\hline
\end{tabular}

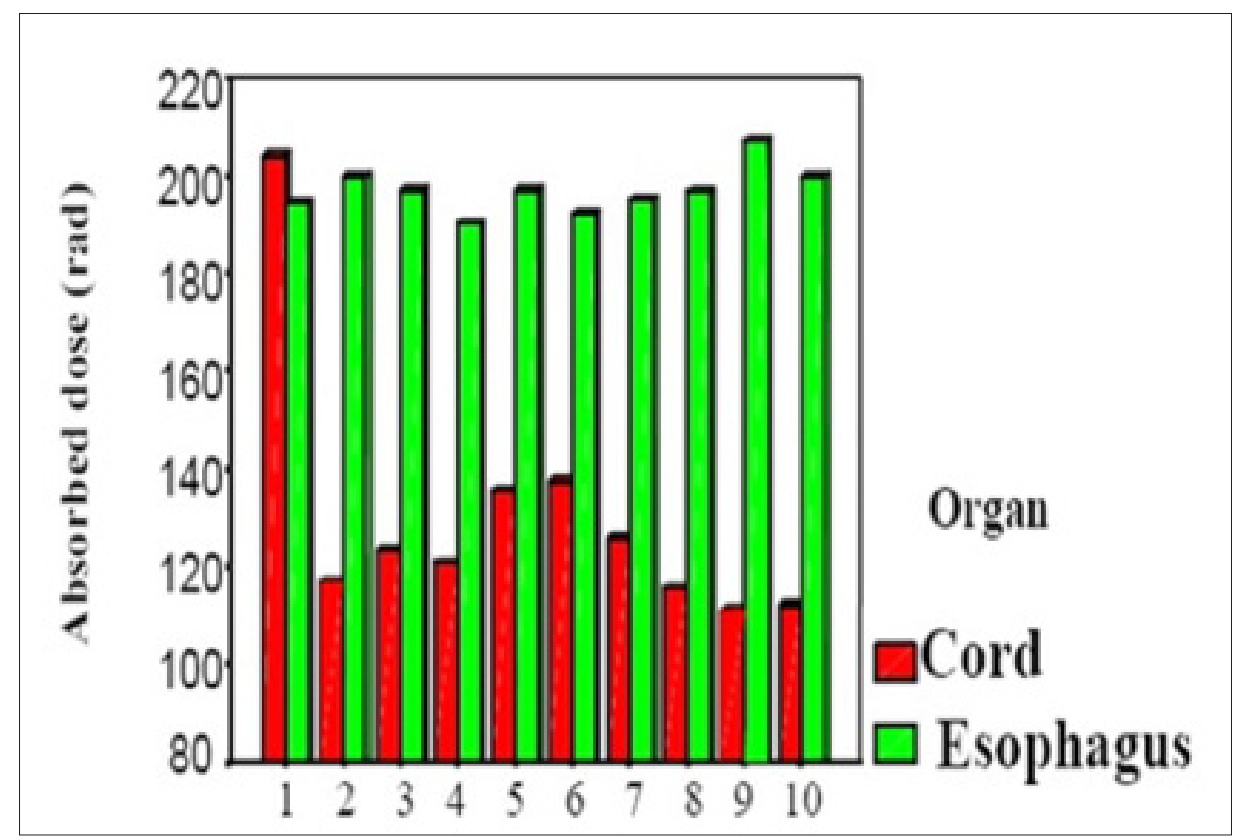

Figure 3: Absorbed dose in spinal cord and esophagus. 


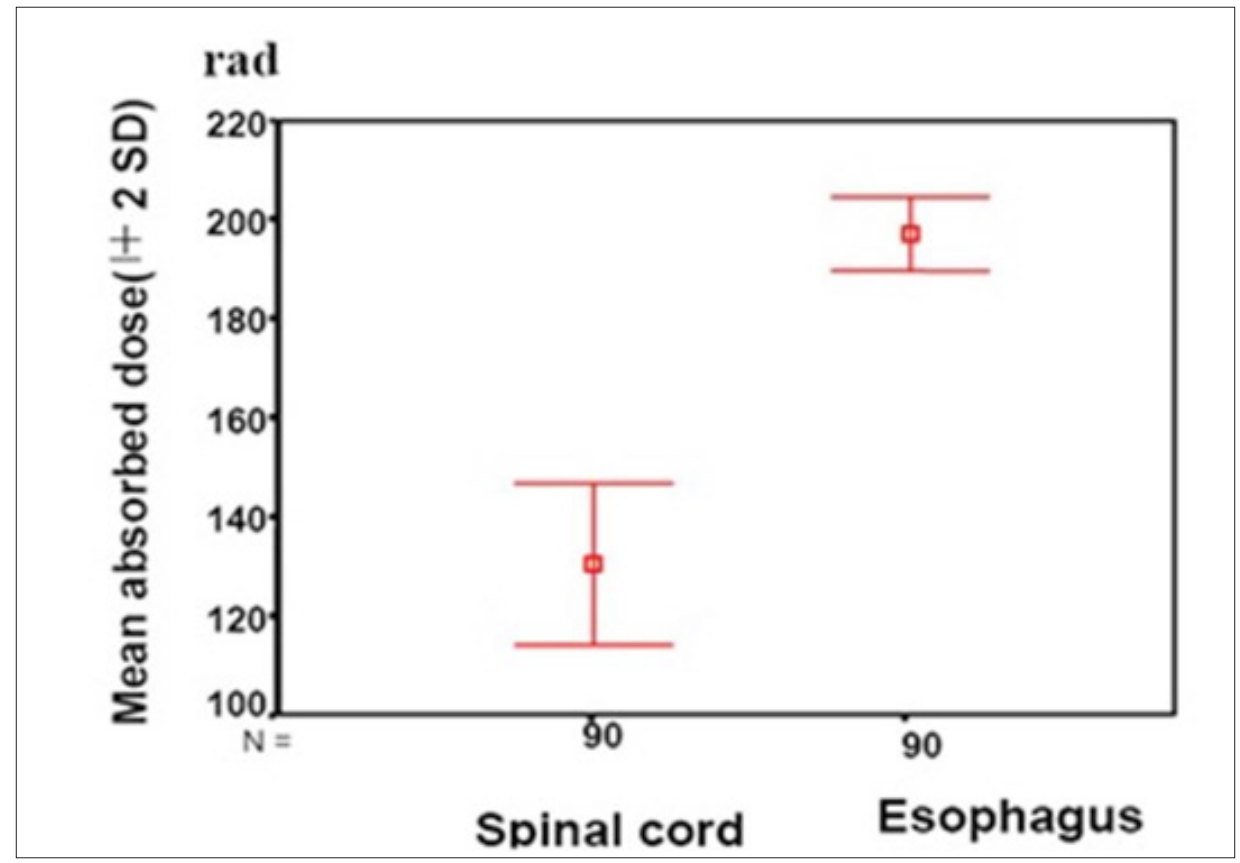

Figure 4: Mean absorbed dose in spinal cord and esophagus.

\section{Discussion}

One of the problems facing the patients who receive radiation for the treatment of tumor in the upper region of the esophagus is the significant dose to the spinal cord as a result of it being in the treatment field in most cases. This problem arises due to the close proximity of esophagus to cervical spinal cord, the obliquity of esophagus and difference in the thickness across the treatment field. Exceeding the tolerance dose of the cord will cause severe side effects such as spinal cord demyelination and consequently resulting in the palsy of the organs. In this study, three special Perspex (Plexiglas) phantoms were designed. Based on our results a better dose homogeneity is achieved for dose delivered to esophagus than corresponding values for spinal cord with right and left anterior oblique wedged technique.

\section{Acknowledgment}

The authors would like to thank research council president for research affairs and office of vice of Mashhad University of medical sciences for their approval and financial support of this work. Thanks, are also given to members of staff and technicians of radiotherapy department of Ghaem hospital and CT-scan department of Razavi hospital of Mashhad-Iran.

\section{References}

1. Khan FM (2012) The physics of radiation therapy. ( $3^{\text {rd }}$ edn), Lippincott williams and wilkins, Philadelphia, Pennsylvania, USA.

2. ICRU (International Commission on Radiation Units and Measurements) (2004) Prescribing, recording and reporting electron beam therapy. ICRU report 71, Oxford university press, USA.

3. Fisher SA, Brady LW, Prez CA (2012) Principles and practice of radiation oncology. ( $3^{\text {rd }}$ edn), Lippincott-Raven Publishers, Philadelphia, Pennsylvania, USA, pp.1241.

4. Roth JA, Lichter AS, Putnam JB, Forastiere AA (2008) Cancer of the Esophagus. In: Devita VT, Helman S, Rosenberg SA(Eds.), Cancer: Principles and Practice of Oncology. (4 ${ }^{\text {th }}$ edn), JB Lippincott, USA, pp. 776.

5. Harshaw TLD Thermos Luminescence Dosimetry, Materials and Assemblies, Bicron NE 6801 Cochran Road, Solon OH 44139, USA.

6. Harshaw TLD Reader, Model 3500 Manual TLD Reader with Win REMS, Operators Manual. 3500-W-0-1299.

For possible submissions Click below: 